\title{
TEMPERATURE VERIFICATION OF HYBRID MICROELECTRONIC CIRCUIT DESIGN
}

\author{
SEDAT ŠrRBEGOVIĆ, MILAN MAZALICA and RATKO KRČ̀MAR \\ Elektrotehnicki fakultet, 78000 Banjaluka, Dr Vase Butozana 3, Yugoslavia
}

(Received October 3, 1981; in final form October 28, 1981)

The paper includes temperature measurement results on hybrid microelectronic circuit surfaces carried out by infrared microscope with special attention to critical temperatures (hot spots) which may require hybrid microelectronic circuit redesign. Critical component reliability analysis, as well as the need for replacement with more reliable components is considered. The principle for hybrid microelectronic design verification suggested.

The paper is the result of longterm efforts at the Rudi Cajavec Factory in Banja Luka, where we have been investigating the possibilities for very reliable hybrid microelectronic circuit design.

\section{INTRODUCTION}

During hybrid microelectronic circuit design special attention has been paid to thermal analysis of some components and microelectronic circuits as a whole. Due to high density of active and passive components in hybrid microelectronic circuits, non-allowable power dissipation and higher temperatures may occur, interfering thus directly with normal operation and diminishing their reliability. As power dissipation and electronic component and circuit reliability represent the most important absolute integrated circuit quality parameters, great attention has been paid to their analysis from the very beginning of design. Computers have been used successfully. A general purpose thermal analysis is available and should be used in all cases where significant amounts of power are dissipated or where lower than normal junction temperatures must be maintained.

Upon realization of designed hybrid microelectronic circuit prototype samples and before its serial production, thermal verification of the project has proved very useful.

Power dissipation in real hybrid microelectronic circuits is accomplished by conduction, covection and radiation. We usually neglect convection and radiation in thermal analysis and reach approximative results through some other simplifications. By comparing measured values, attained in real conditions, with calculated values we are not only able to recognize thermal analysis precision and some approximations justification, but also to identify possible faults which might have appeared either in the course of design or during hybrid circuit manufacture.

\section{TEMPERATURE MEASUREMENT}

A hybrid microelectronic circuit with relatively high power dissipation, in which some components will be heated to unacceptably high temperature levels, has been examined in this paper.

In particular a R26 resistor in the $\mathrm{VI}_{1}$ resistor network (Figure 1) will under room conditions reach a temperature of $140^{\circ} \mathrm{C}$ when the circuit is operating. The temperature of the thin film ceramic substrate on which (the resistor is located) is well above $125^{\circ} \mathrm{C}$, interfering with the reliable operation of the whole circuitry, according to MIL-HDBK217C. This fact is sufficient reason for all our attention to be paid to the relevant resistor network. 


\subsection{Hybrid Microelectronic Circuit Description.}

The observed microelectronic circuit has been realised on thick film ceramics with dimensions $37.3 \times 22.2 \times 0.63 \mathrm{~mm}^{3}$ which are placed on a Pertinax plate with diameter of $65 \mathrm{~mm}$. Five layers (three conductive and two dielectric) have been put on the ceramics by the sieve printing method, with a total of eight printings (dielectric layers have been printed twice). The geometrically perceived circuit (Figure 1) is of medium density and the components are not uniformly arranged in a thermal sense. In the operation regime the circuit consumes a current of $60 \mathrm{MA}$ at supply voltage of $40 \mathrm{~V}$.

\subsection{Measuring Apparatus}

An infrared radiometric microscope model RM-2A, Barnes Engineering Co, with $35 \mu \mathrm{m}$ objective resolution and temperature resolution of $0.5^{\circ} \mathrm{C}$ at room temperature has been used for temperature measurement.

\subsection{Measurement Description.}

Measurements were carried out at room temperature of $24^{\circ} \mathrm{C}$ and relative humidity of $50 \%$. According to a preliminary assigned $1.3 \mathrm{~mm}$ raster the measurements were carried out on a hybrid microelectronic circuit surface, on a total of 400 spots $(25 \times 16)$. Measurement results have been graphically interpreted in Figure 2, with temperatures put on spots in such a way as to give the impression of temperature space arrangement of the hybrid surface.

\section{MEASURING RESULTS DISCUSSION}

In order to better understand the graphics in Figure 2 one should be aware that the temperatures are the lowest on the surface conductive layer with the exception of that

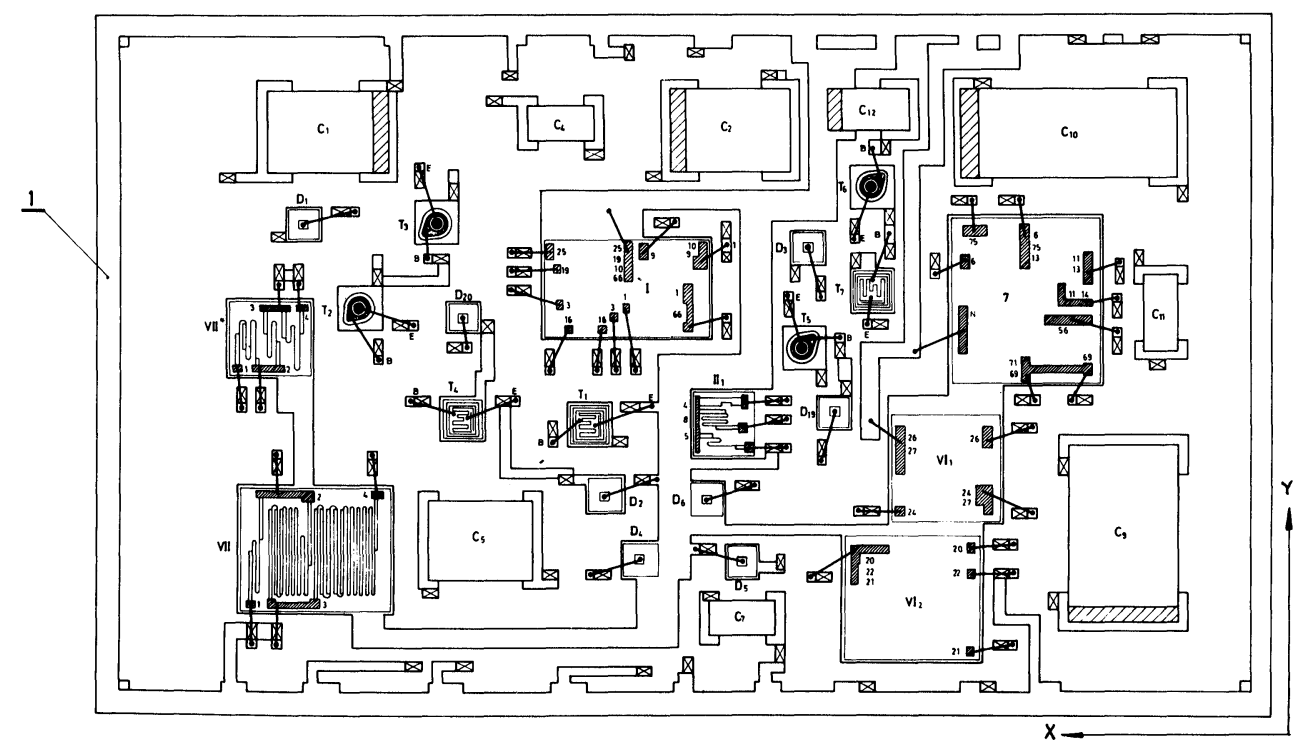

FIGURE 1 Layout of circuit examined. 


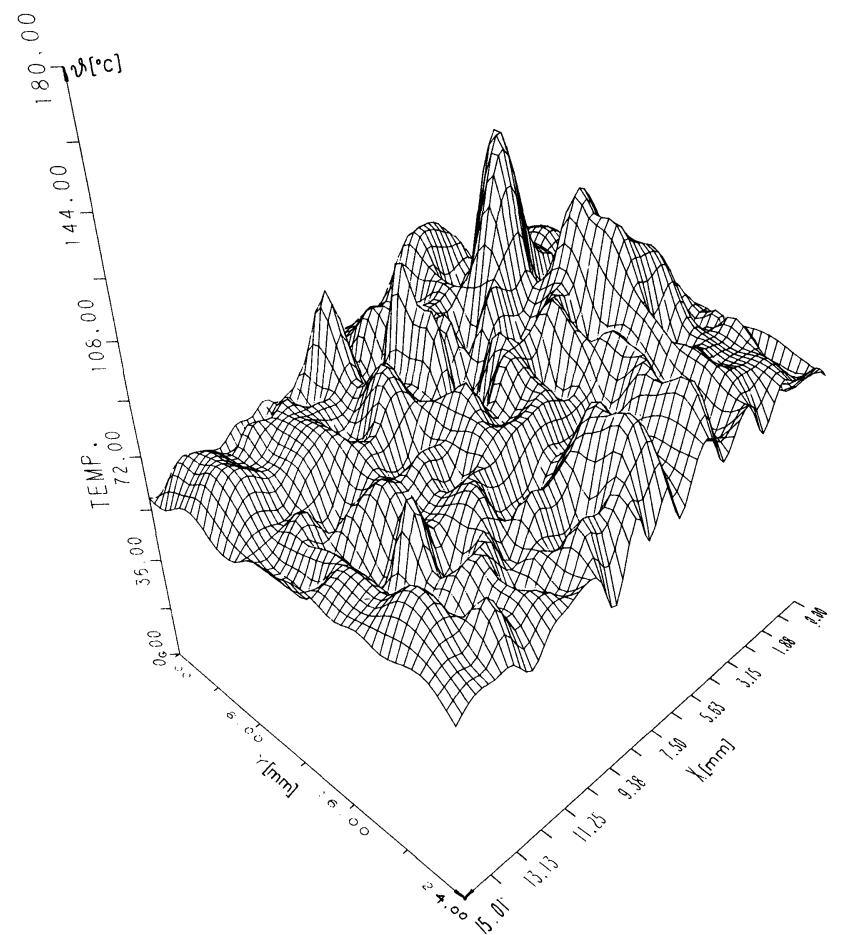

FIGURE 2 Temperature distributor or hybrid circuit surface.

layer being placed above the conductive layer. Temperatures are higher on thin layer ceramics with resistor networks, while the temperatures are the highest in the middle of the resistor, on zener diodes and power transistors. Temperature on the R26 resistor surface is specially emphasized in Figure 2. The high temperature of this resistor, as said before, interferes with the reliable operation of the whole circuit. Therefore special attention has been paid to that resistor and the whole $\mathrm{VI}_{1}$ resistor network. The $\mathrm{VI}_{1}$ resistor network is electrically connected to capacitors, zener diodes and power transistors, which might have also contributed to its heating, without being decisive for such a high temperature.

As the R26 resistor showed the highest temperature, it was worth trying to disconnect it from the hybrid microelectronic circuit and to analyse the effects of this dislocation. In studying this possibility indices were replaced on the R24 and R26 resistors in the design phase. As the resistor network, as a whole, has a certain symmetry as far as assembly is concerned, the position of the R24 and R26 resistors has been changed. As a result of this fault, instead of a $7.5 \mathrm{k} \Omega$ resistor with $97 \mathrm{~mW}$ dissipation we installed a $910 \Omega$ resistor with $2 \mathrm{~mW}$ dissipation which has one terminal connected to the supply source. The facts themselves are sufficient in explaining the heating of the observed resistor, resistor network and its vicinity. After elimination of this fault, temperatures were measured again at the same places and interpreted graphically (Figure 3). Fault elimination effects are easily noticeable upon comparing the results interpreted in the graphics (Figures 2 and 3). In order to illustrate these effects even better, temperatures on all resistors in the $\mathrm{VI}_{1}, \mathrm{VI}_{2}$ and 7 resistor networks (Figure 1) have been measured before fault indentification $(v)$ and after its elimination $\left(v^{1}\right)$ and the results are shown in Table 1. 


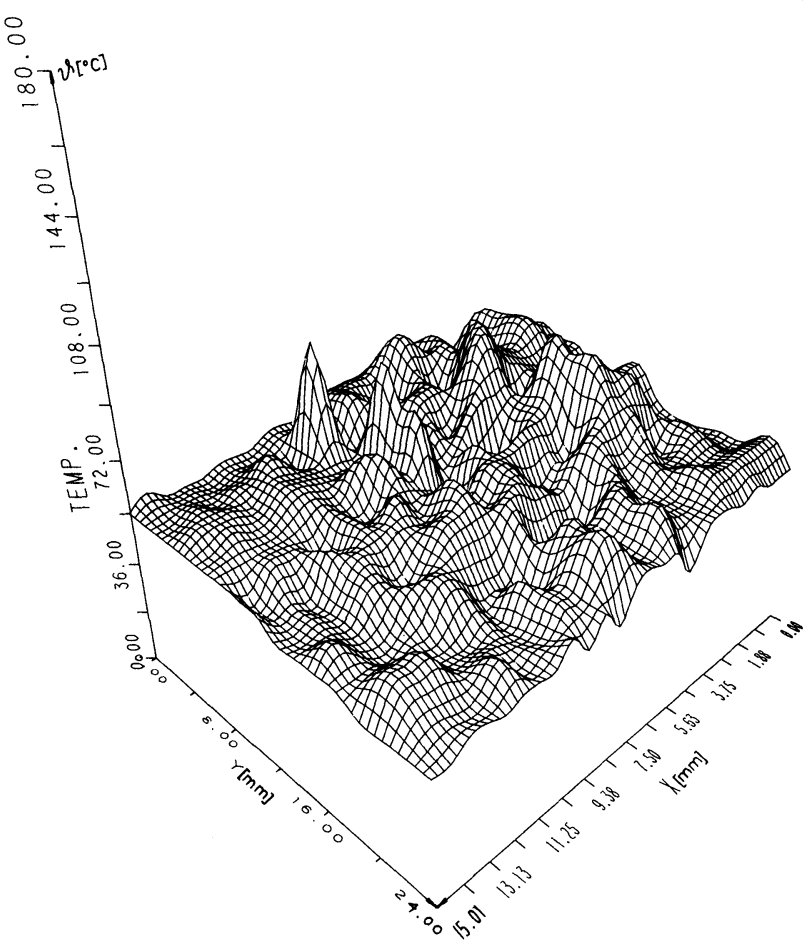

FIGURE 3 Temperature distribution on hybrid circuit surface using modified components.

TABLE I

\begin{tabular}{lrrrrrrrrrrrrrr}
\hline Resistor & $\mathrm{R}_{6}$ & $\mathrm{R}_{11}$ & $\mathrm{R}_{13}$ & $\mathrm{R}_{14}$ & $\mathrm{R}_{20}$ & $\mathrm{R}_{21}$ & $\mathrm{R}_{22}$ & $\mathrm{R}_{24}$ & $\mathrm{R}_{26}$ & $\mathrm{R}_{27}$ & $\mathrm{R}_{56}$ & $\mathrm{R}_{69}$ & $\mathrm{R}_{71}$ & $\mathrm{R}_{75}$ \\
\hline$\nu\left({ }^{\circ} \mathrm{C}\right)$ & 112 & 107 & 105 & 115 & 103 & 103 & 104 & 117 & 140 & 131 & 113 & 110 & 119 & 104 \\
$\nu^{1}\left({ }^{\circ} \mathrm{C}\right)$ & 77 & 76 & 75 & 80 & 69 & 71 & 71 & 82 & 78 & 86 & 78 & 76 & 83 & 73 \\
\hline
\end{tabular}

\section{CONCLUSION}

Faults which appeared either in the course of design or realisation can be simply identified by thermal verification of the designed hybrid microelectronic circuit. The cause of the fault is identified by analysis of critical spots i.e. components in which non-allowable high temperatures appear. It is possible to redesign the resistors, i.e. resistor networks, by enlarging their surfaces, i.e. by using special tabs with larger surfaces of kovar or beryllia if power transistors are in question. It is assumed that there is enough room for this on the upper layer. As, whenever possible, emergency tabs are left in the course of design it is sometimes possible to dislocate a critical component from the hybrid circuit in the PC board.

\section{REFERENCES}

1. Hybrid Design Manual, (Teledyne Microelectronics, Los Angeles, 1976).

2. Handbook of Thin Film Technology, (McGraw-Hill Book Company).

3. Colins Radio Company, Hybrid Design Manual, (17 November 1972).

4. S. Prussin, Thermal Considerations in Package Design.

5. MIL-HDBK-217C, 9 A pril 1982, pp 2, 5, 3.

6. L.G. Walslak, E.W. Poola, "Thermal Resistance Measurement by IR Scanning", Microwave J, 20, No 2, 62-65 1977.

7. V. Kale, Thermal Analysis of Singer Transmitter/Receiver.

8. Instruction Manual Infrared Radiometric Microscope, Model RM-2A, Barnes Engineering Co. 

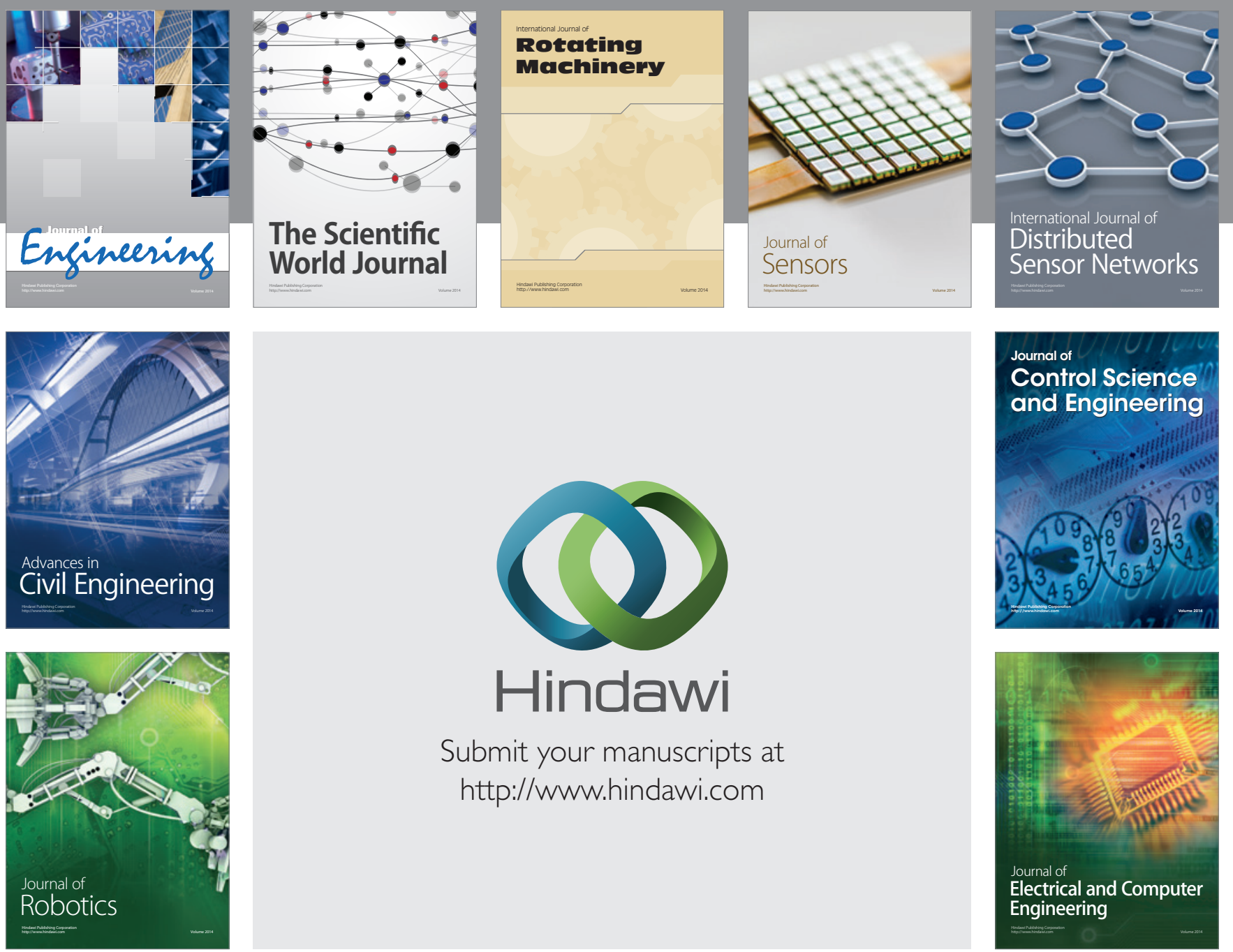

Submit your manuscripts at

http://www.hindawi.com
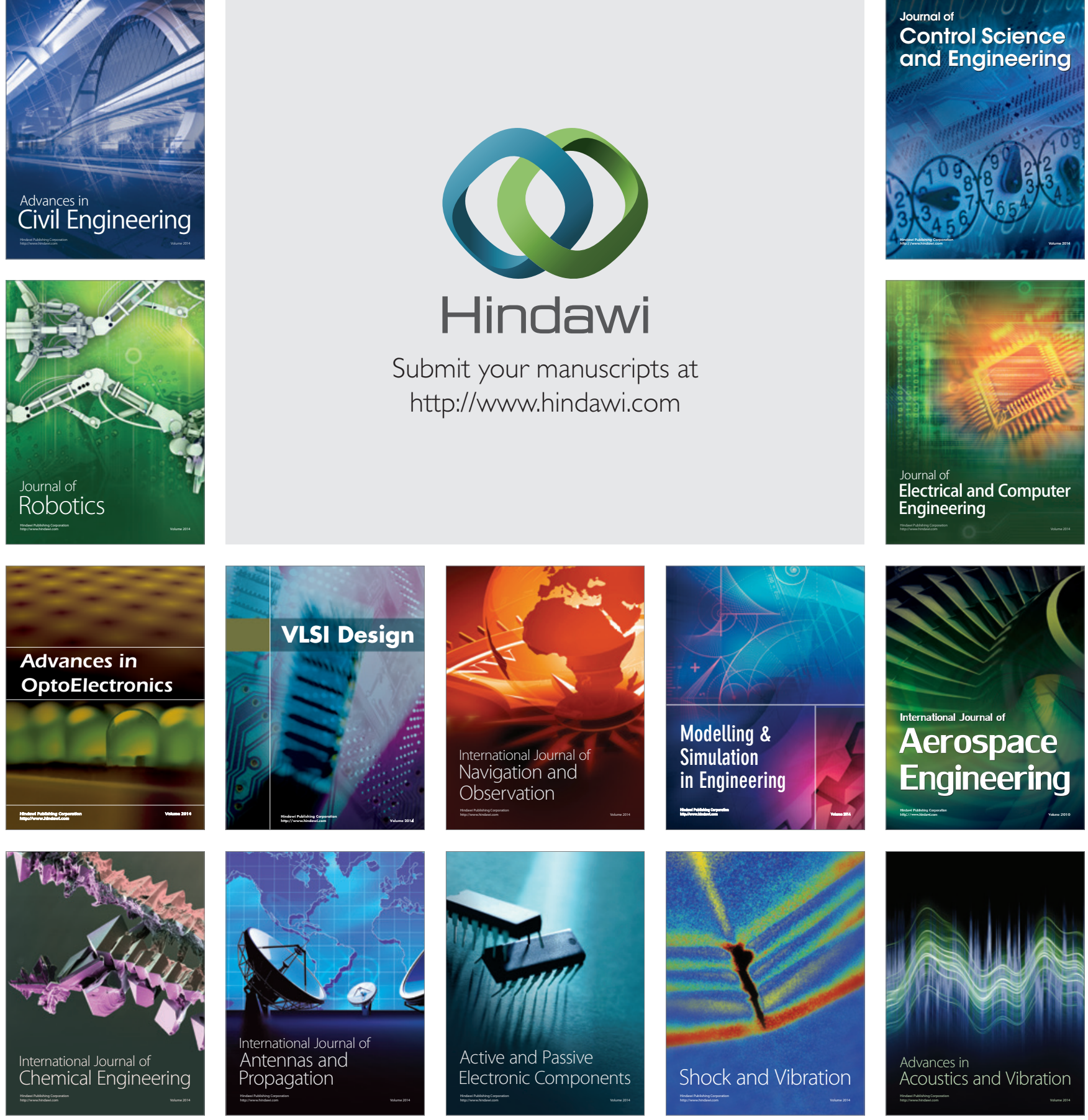